\title{
Article \\ Graphene for the Building of Electroanalytical Enzyme-Based Biosensors. Application to the Inhibitory Detection of Emerging Pollutants
}

\author{
Marta Bonet-San-Emeterio (D), Noelia Felipe Montiel (D) and Manel del Valle *(D) \\ Sensors and Biosensors Group, Department of Chemistry, Universitat Autònoma de Barcelona, Edifici CN, \\ 08193 Bellaterra, Spain; marta.bonet@uab.cat (M.B.-S.-E.); Noelia.FelipeMontiel@uantwerpen.be (N.F.M.) \\ * Correspondence: manel.delvalle@uab.es; Tel.: +34-93-5813235
}

check for

updates

Citation: Bonet-San-Emeterio, M.; Felipe Montiel, N.; del Valle, M. Graphene for the Building of Electroanalytical Enzyme-Based Biosensors. Application to the Inhibitory Detection of Emerging Pollutants. Nanomaterials 2021, 11, 2094. https://doi.org/10.3390/ nano11082094

Academic Editors: Daniela Iannazzo and Run Zhang

Received: 18 June 2021

Accepted: 13 August 2021

Published: 18 August 2021

Publisher's Note: MDPI stays neutral with regard to jurisdictional claims in published maps and institutional affiliations.

Copyright: (c) 2021 by the authors. Licensee MDPI, Basel, Switzerland. This article is an open access article distributed under the terms and conditions of the Creative Commons Attribution (CC BY) license (https:/ / creativecommons.org/licenses/by/ $4.0 /)$.

\begin{abstract}
Graphene and its derivates offer a wide range of possibilities in the electroanalysis field, mainly owing to their biocompatibility, low-cost, and easy tuning. This work reports the development of an enzymatic biosensor using reduced graphene oxide (RGO) as a key nanomaterial for the detection of contaminants of emerging concern (CECs). RGO was obtained from the electrochemical reduction of graphene oxide (GO), an intermediate previously synthesized in the laboratory by a wet chemistry top-down approach. The extensive characterization of this material was carried out to evaluate its proper inclusion in the biosensor arrangement. The results demonstrated the presence of GO or RGO and their correct integration on the sensor surface. The detection of CECs was carried out by modifying the graphene platform with a laccase enzyme, turning the sensor into a more selective and sensitive device. Laccase was linked covalently to RGO using the remaining carboxylic groups of the reduction step and the carbodiimide reaction. After the calibration and characterization of the biosensor versus catechol, a standard laccase substrate, EDTA and benzoic acid were detected satisfactorily as inhibiting agents of the enzyme catalysis obtaining inhibition constants for EDTA and benzoic acid of 25 and $17 \mathrm{mmol} \cdot \mathrm{L}^{-1}$, respectively, and a maximum inhibition percentage of the $25 \%$ for the EDTA and $60 \%$ for the benzoic acid.
\end{abstract}

Keywords: graphene; biosensing; inhibition; phenols; laccase enzyme

\section{Introduction}

A chemical sensor is defined by IUPAC as a device that transforms chemical information into an useful analytical signal [1]. The use of sensors has progressed over the years with the constant development of new technologies and devices. Researchers try to improve the selectivity of these designs with a wide range of techniques, such as the modification of the transducer material, the use of chemometric data processing, or the inclusion of sample pretreatment. An example of the former is the concept of biosensors. A biosensor may be described as a sensor combined with a recognition element from the biological world, which is the one responsible for conferring paramount selectivity. Actually, this is what makes the difference from common sensors and grants their success. Since the discovery of graphene and its derived products, they have been gaining importance in the sensors and biosensors field [2]; one of the reasons for this is due to their synergistic effect when they are implemented as transducing materials $[3,4]$. It can be proven that the usage of graphene is becoming widespread when you search how many publications exist with "graphene" as a keyword, since 2004, when graphene was strictly discovered. Almost 150,000 publications can be listed in total; from these, 14,117 can be found using the "graphene + sensor" keyword combination (data according to Scopus database).

Among others, graphene and its derivates have gained popularity in electroanalysis due to their interesting inherent properties, such as biocompatibility, low-cost raw materials, and their easy tuning [3,4]. In this work, graphene is used not only as a key material to 
enhance the response of a bare electrochemical sensor, but also to show its properties as a linkage platform for enzyme immobilization [5-7]. Graphene allows to avoid sensor pretreatment or modifications that can be costly, time-consuming, and complex. One example is electrochemical grafting, where the carboxylic groups of an organic layer are attached to a conductive surface [8-10].

Graphene synthesis can be classified into two groups: top-down, and bottom-up synthesis. Furthermore, new strategies may be mentioned in the state of the art of the topic; for example, the cracking of multiwalled carbon nanotubes to create graphene oxide (GO)ribbons [11,12]. Bottom-up syntheses are the ones that start from simple carbon structures to create a pristine single-atom graphene layer with minimum defects and a sp2 configuration. Some examples of bottom-up approaches are the chemical vapor deposition (CVD) or the epitaxial growth $[13,14]$. Nevertheless, these synthetic pathways have important drawbacks, such as the complex adaptation to large scale production and the expensive and complex arrangements [15]. For this reason, top-down syntheses are popular when large amounts of materials are required. Hummers' synthesis is the most frequently used method for the top-down production of graphene $[16,17]$. This wet synthesis uses strong oxidizing agents for exfoliating graphite to GO. As it is known, GO is a hydrophilic nonconductive material, which needs further synthetic steps to recover the pristine graphene properties, one of them the conductivity, an essential feature in electrochemistry $[15,17]$. Thus, a further step is needed, the GO conversion to the reduced graphene oxide (RGO). This step can be done electrochemically, chemically, mechanically, or even thermally. Even though, in the sensors study area, the most used reduction techniques are the electrochemical and the chemical [18-20]. Both methods are interesting due to their reproducibility and easy applicability; however, the electrochemical approach presents several clear advantages over the chemical approach, e.g., low-cost, speed, environmentally friendliness and simplicity [20]. Therefore, in this work, RGO has been produced electrochemically. This method is based on the reduction of oxidized moieties present on the GO surface. As an additional advantage, the electrochemical reduction allows to easily and effectively control the oxidation degree of the RGO by simply adjusting the applied potential, which may be interesting for different final applications [21,22].

Graphene is not the unique strategic nanomaterial used to enhance the sensors response. For example, carbon dots and nanotubes have been also widely used as electrode modifiers. Carbon dots, also named graphene quantum dots or carbon nanodots, are a new trend in electroanalysis applications. Up to recent times, this material has been used mainly in photoluminescence-based determinations; but in current years it is growing strongly also in the electrochemical field [23-26]. On the other side, carbon nanotubes, considered as a rolled layer of graphene [27], have been extensively studied as a sensor modifier as well. Like other materials from the carbon family, carbon nanotubes ascribe catalytic effects and sensing improvements to the electrode behavior [28-30].

Enzymes such as laccase, tyrosinase, and glucose oxidase have been employed for a long time in bioanalytical chemistry, especially in biosensing. Their relevance is related to their ability to interact only with their matching substrates, conferring to the device one of the most desired characteristics: the specificity and the ability to distinguish the analyte in complex matrices. One of the most famous case is the glucose biosensor, already commercialized as a device for diabetic patients [31,32]. On the other side, laccase, a protein with a copper nucleus, has been extensively studied as a biorecognition element in various areas owing to its ability to oxidize a wide range of phenolic compounds, being catechol one of the standards for its activity analysis $[33,34]$. But not only there have been studies on the direct interaction with the substrates, but also on the interaction of the enzymes with their inhibitors. An interesting example is its use in detecting pollutants in products for human consumption, especially in drinking water. UNESCO reports as a pollutant any synthetic or naturally occurring chemical or microorganism that is not commonly monitored or regulated in the environment. This group includes pharmaceuticals, personal care products, pesticides, industrial additives, and industrial and household products [35]. 
New pollutants, also named emerging pollutants or contaminants of emerging concern (CECs), are appearing continuously. These chemicals have become an increasing problem over the years. Fortunately, at the same time, technology has been developed which has introduced new and improved methods to isolate and/or detect CECs in human consumption products. However, the existing commercial techniques are time-consuming and expensive, which encourages researchers to find new alternatives. Moreover, it must be considered that at this moment there are no reference methods in the European legislation to control the presence of these compounds in water. Nevertheless, different factors will force their consideration in the near future. The first reason is the conclusions from recently published articles, which determine that certain CECs, in special endocrine disruptors, interfere in the human and animal endocrine system [36-38]. The second reason is that these pollutants are not only found in water but also in soil and marine species such as shellfish and oily fish, increasing the contact of humans with these compounds with still unknown long-term effects. This work reports the preparation and characterization of a laccase-graphene biosensor for the detection of CECs (EDTA and benzoic acid) by the inhibition of the laccase enzyme.

\section{Materials and Methods}

\subsection{Chemical and Reagents}

All reagents were of an analytical grade and all solutions were prepared using deionized water from Milli-Q system (Millipore, Billerica, MA, USA). Samples for electrochemical measurements were prepared on phosphate buffer in the presence of $\mathrm{KCl}$ as a background electrolyte, reagents purchased from Merck KGaA (Darmstadt, Germany).

For the graphene synthesis, it was used as a graphite powder $(50 \mu \mathrm{m}$, sulfuric acid (98\%), sodium nitrate (99\%), and potassium permanganate (99\%), purchased from Merck KGaA (Darmstadt, Germany); hydrogen peroxide (30\%) was purchased from Riedel-de Haën (Germany). Used ionic resins were strong cationic resin C100E and weak anionic resin A520E (Purolite) purchased from Merck KGaA. Ba( $\left(\mathrm{NO}_{3}\right)_{2}$ was purchased at Acros Organics (Geel, Belgium).

The material needed for the building of the electrode were: Resineco Epoxy Kit 125 resin supplied from Resineco green composites (Barcelona, Spain) and graphite powder (particle size $<50 \mu \mathrm{m}$ ) was received from BDH (BDH Laboratory Supplies, Poole, UK). For the biosensor, Laccase from Agaricus Bisporus, $7.2 \mathrm{U} \cdot \mathrm{mg}^{-1}$ (EC number: 420-150-4), 1-ethyl-3-(3-dimethylaminopropyl carbodiimide (EDAC), and N-hydroxysulfosuccinimide (sulfo-NHS) (purchased from Merck KGaA) were used.

Finally, catechol, acid benzoic, and EDTA were purchased from Merck KGaA.

\subsection{Electrochemical Measurements}

Voltammetric measurements were performed on a AUTOLAB PGSTAT30 (Ecochemie, Netherlands) controlled by GPES software. Electrochemical Impedance Spectroscopy (EIS) experiments were performed on a Bas-Zahner IM6e (Kronach, Germany) potentiostat controlled by Thales software. For both electrochemical techniques a typical three electrode circuit was used. In the used assembly it can be found: the working electrode based on a graphite epoxy composite (electrode already optimized in our laboratory [39-41]), an $\mathrm{Ag} / \mathrm{AgCl}\left(0.1 \mathrm{~mol} \cdot \mathrm{L}^{-1} \mathrm{KCl}\right)$ electrode as a reference and a Pt electrode as a counter. All measurements were carried out at room temperature without stirring using as an electrolyte solution phosphate buffer $50 \mathrm{mmol} \cdot \mathrm{L}^{-1}+\mathrm{KCl} 100 \mathrm{mmol} \cdot \mathrm{L}^{-1}$ at $\mathrm{pH} 7.4$.

Parameters for the cyclic voltammetry (CV) measurement were optimized for its use; at the end, a scan rate of $10 \mathrm{mV} \cdot \mathrm{s}^{-1}$ and a step potential of $0.001 \mathrm{~V}$ was applied. The analysis of CV was performed with the GPES software, in particular using the inset tool to calculate the base line and the corresponding peak height of the recorded data. 


\subsection{Sensor Characterization}

Morphological characterization of the raw materials was carried essentially by Transmission Electron Microscopy (TEM); TEM images were obtained using a JEOL JEM-2011 microscope. Moreover, X-ray photoelectron spectroscopy (XPS) analysis was carried out to describe the structure of the synthetized GO; a SPECS PHOIBOS 150 hemispherical energy analyzer with monochromatic $\mathrm{Cu}-\mathrm{K} \alpha$ radiation was used. CasaXPS software was used to acquire the fitted values.

Surface roughness assessment was done by processing of topographic atomic force microscopy (AFM) images obtained using a Veeco Dimension 3100 AFM Microscope (Bruker, Billerica, MA, USA).

\subsection{Graphene Synthesis and Characterization}

A top-down synthesis based on a modified Hummers' method was used for the synthesis of GO [16,18,42]. In short, the protocol consists of the addition of $1.5 \mathrm{~g}$ of graphite and $4.5 \mathrm{~g}$ of $\mathrm{NaNO}_{3}$ to $35 \mathrm{~mL}$ of sulfuric acid $(98 \%)$ cooled at $0{ }^{\circ} \mathrm{C}$. Afterwards, $4.5 \mathrm{~g}$ of $\mathrm{KMnO}_{4}$ in fine powder form was added in small portions over a period of $2 \mathrm{~h}$, avoiding temperature from rising and the mixture was stirred for an additional $4 \mathrm{~h}$. The resulting mixture was heated at $35^{\circ} \mathrm{C}$ for $30 \mathrm{~min}$ and the oxidation process was completed by slowly adding $75 \mathrm{~mL}$ of deionized water. In this highly exothermic step, it is important to avoid boiling. The reaction finishes $15 \mathrm{~min}$ after being kept at $70^{\circ} \mathrm{C}$. In order to eliminate unreacted oxidizing compounds, the solution was treated with $300 \mathrm{~mL}$ of $10 \%$ hydrogen peroxide. The resulting brown paste (the densest GO) was washed multiple times with deionized water, recovering the solid by centrifugation at $6000 \mathrm{rpm}$. This process was repeated several times, till the $\mathrm{pH}$ approached neutrality. With a $\mathrm{pH}$ close to 7 , the sample of GO was treated with cation and anion exchange resins to eliminate the remaining salt impurities. This was done just by placing in contact, under vigorous stirring, the sample and resin for $30 \mathrm{~min}$. The separation was achieved by using a $50 \mu \mathrm{m}$ sieve. Sulfate ions were eliminated with $\mathrm{Ba}\left(\mathrm{NO}_{3}\right)_{2}$. Finally, the obtained slurry was dried in a vacuum oven at $60^{\circ} \mathrm{C}$ for $48 \mathrm{~h}$.

\subsection{Graphene Oxide Modification and Immobilization of the Enzyme for the Biosensor Building}

The graphite epoxy composite (GEC) electrode, used as base transducer, had an average geometric area of $28 \mathrm{~mm}^{2}$ ( $\varnothing=6 \mathrm{~mm}$ ), as it is specified in the reference bibliography $[39,40,43]$; the composite conductive paste was added in an assembly formed by an electrical connector and a PVC tube. Afterwards, the conductive material was hardened in an oven at $40^{\circ} \mathrm{C}$. Finally, the electrode was polished with different grain sandpapers until a homogeneous and pristine surface was obtained. The polishing step can be applied when needed to regenerate the surface and obtain again the bare platform. Figure 1 sketches the construction process.

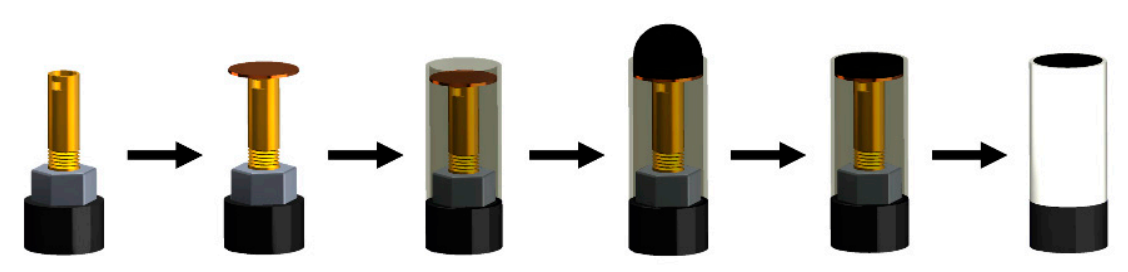

Figure 1. Scheme of the mechanic assembly for the construction of the base graphite-epoxy voltammetric transducer.

Once the conductive element of the proposed biosensor was ready, it was modified with GO. The selected technique to modify the electrode surface was drop casting, based on the physical adsorption of the GO to the base carbon material. Firstly, $40 \mu \mathrm{L}$ of the GO dispersion $\left(1 \mathrm{mg} \cdot \mathrm{mL}^{-1}\right.$ in deionized water) was deposited on the GEC electrode. It may be noted that the GO suspension must be sonicated previously for $1 \mathrm{~h}$ and centrifugated for 
$1 \mathrm{~min}$ at $800 \mathrm{rpm}$ to use only the part of the dispersion that content the flakes with fewer layers. After this, the electrode was dried at $40^{\circ} \mathrm{C}$ to promote physisorption. The RGO was obtained by the electrochemical reduction of the previous electrode. As it was first optimized [43], the reduction was carried out via CV; in particular, 10 cycles were applied in a potential range going from $+1.90 \mathrm{~V}$ to $-2.30 \mathrm{~V}$ at $0.1 \mathrm{~V} \cdot \mathrm{s}^{-1}$.

The laccase enzyme was covalently bonded to the RGO via carbodiimide (EDAC, $\mathrm{N}$-(3-dimethylaminopropyl)-N'-ethylcarbodiimide hydrochloride) chemistry. The EDAC reaction proved to be the most suitable strategy to immobilize the enzyme since it is able to react (through a free amino group) with the remaining carboxylic groups from RGO (that were not reduced in the reduction step) to obtain the amide bond. Concretely, after the reduction, a solution of $10 \mathrm{mg} \cdot \mathrm{mL}^{-1}$ of laccase in water was prepared, where $100 \mu \mathrm{L}$ of EDAC solution (1000 ppm) and $50 \mu \mathrm{L}$ of sulfo-NHS solution (1000 ppm) were added. Once the solution was homogenized, the RGO electrode was incubated overnight in an Eppendorf tube [44-47]. The last step was to clean the non-bonded compounds from the surface of the electrode by rinsing it for $1 \mathrm{~h}$ in the working phosphate buffer.

As Figure 2 depicts, the EDAC coupling agent is used to activate the carboxylic groups from the RGO surface and form an intermediate complex that can react with the primary amine group from the laccase chain. In this article, sulfo-NHS was additionally used to obtain a more stable and efficient intermediate complex.

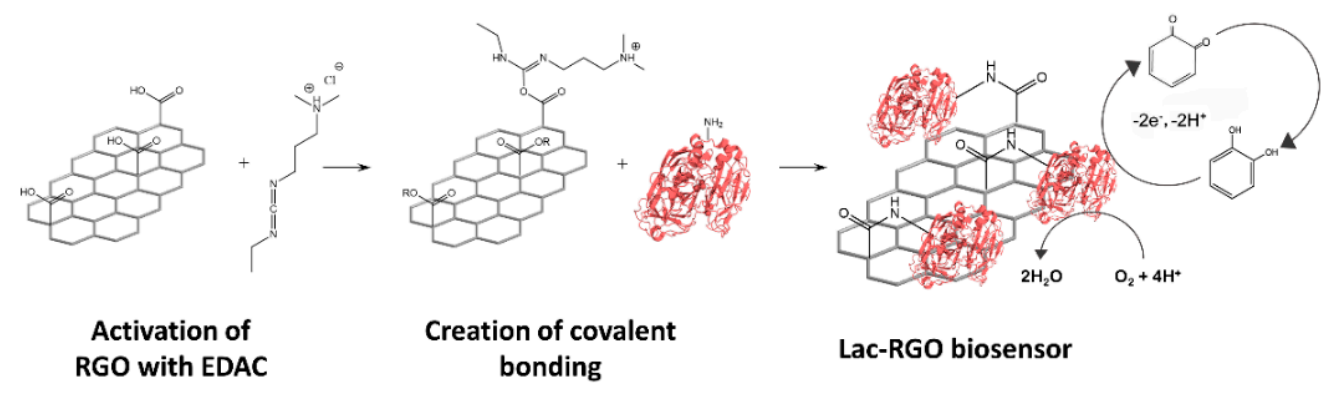

Figure 2. Scheme of the laccase immobilization. Step 1: activation of the RGO using EDAC (and NHS to increase the efficiency), Step 2: bonding creation between the primary amine from the enzyme and the intermediate complex of the RGO surface. Finally, the catalytic reaction is described.

\section{Results}

\subsection{Study of the Synthesized Graphene Oxide}

The obtained GO was characterized by TEM. Figure 3 shows some representative images resulting from this technique. Herein, the main part of graphene flakes was thin and transparent enough to see the CuTEM grid through them. The presence of GO was corroborated when its characteristic wrinkles were identified, present, for example, in Figure $3 \mathrm{~A}, \mathrm{~B}, \mathrm{D}[48,49]$. The main presence of few layers of aggregates, which is supported because not only the transparency is achieved but also clear borders, is also noticed. Particularly, in Figure 3A,D can be seen clear and sharp edges, whereas in Figure 3B the presence of a large number of layers can be deduced from the multiple grey shades at the edge of the flake. These hypotheses were compared with the literature, where other researchers have similar TEM images [22,50,51]. The opaque materials in Figure 3C may be associated with the graphite residues coming from the starting synthesis reagents. 

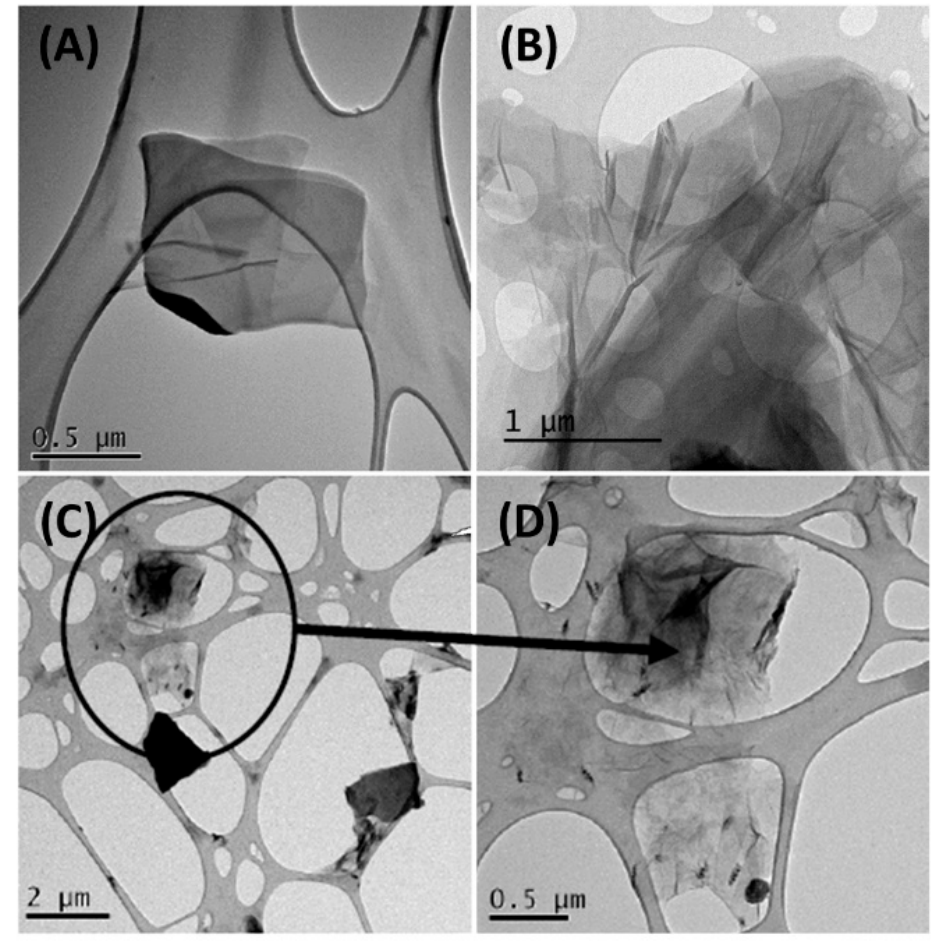

Figure 3. TEM images of synthesized GO. The samples were suspended in ethanol absolute ( $\geq 99 \%)$ and casted on a CuTEM grid. $(\mathbf{A}, \mathbf{C})$ show entire flakes of graphene oxide meanwhile in figures $(\mathbf{B}, \mathbf{D})$ it is presented a specific part where graphene characteristics can be spotted.

In addition to TEM, XPS analysis was carried out to study the obtained GO (Figure 4). Table 1 presents the dominating groups assigned to $C 1$ s core level after its deconvolution. Different groups could be found in the material, corresponding to the wide range of oxygen functional groups from the synthetic pathway. To confirm this hypothesis, the oxygen and carbon ratio was calculated, being equal to 2.14. Normally, the approved ratio values range between 2.1 and 2.9 for GPO samples [16].

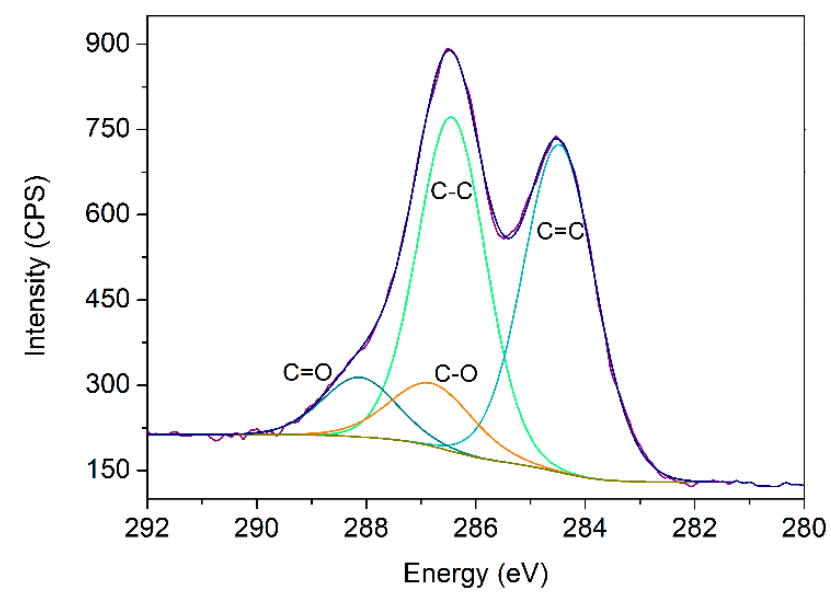

Figure 4. GO-Fitted XPS spectra of $\mathrm{C}$ 1s and its deconvolution. Blue line corresponds to the fitted curve. 
Table 1. XPS-obtained distributions for the synthetized GO for the C 1s spectra.

\begin{tabular}{ccc}
\hline Bond & Energy $(\mathrm{eV})$ & \% Area (RSD) \\
\hline C $=\mathrm{C}$ & 284.5 & $42.81(1.30 \%)$ \\
$\mathrm{C}-\mathrm{C}$ & 286.4 & $40.39(2.1 \%)$ \\
$\mathrm{C}-\mathrm{O}$ & 286.9 & $10.24(8.3 \%)$ \\
$\mathrm{C}=\mathrm{O}$ & 288.2 & $6.56(9.5 \%)$ \\
\hline
\end{tabular}

* Relative standard deviation.

Briefly, the resulting material of the modified Hummers' method has similar properties and characteristics to comparable works in the literature $[17,20,22,52]$, reflecting then the good performance.

\subsection{Modification and Characterization of the Graphene Sensor}

The optimization of the sensor assembly was carefully addressed. First, the optimal amount of GO solution to be deposited onto the electrode was studied. In this case, dropcasting was chosen as the modification method, due to its rapid and easy application. The effect of four different volumes $\left(20,30,40\right.$, and $50 \mu \mathrm{L}$ ) of a $1 \mathrm{mg} \cdot \mathrm{mL}^{-1} \mathrm{GO}$ dispersion (in deionized water) was studied. As mentioned above, GO is not conductive. For this reason, after the deposition, it was reduced to RGO to analyze its response using electrochemical techniques. The analytical performance was studied by using a CV technique, by measuring the height of the oxidative peak at a potential of $0.18 \mathrm{~V}$ (vs. $\mathrm{Ag} / \mathrm{AgCl}$ reference electrode) in the electrochemical standard $\left[\mathrm{Fe}(\mathrm{CN})_{6}\right]^{3-/ 4-} 5 \mathrm{mmol} \cdot \mathrm{L}^{-1}$ (diluted in phosphate buffer $50 \mathrm{mmol} \cdot \mathrm{L}^{-1}$ at $\mathrm{pH}$ 7.4) as analyte. The goal was to find a volume that covers all the electrode surface and did not saturate the response. As can be observed in Figure 5A, the obtained results, together with visual checking, demonstrate that smaller volumes did not cover the whole area of the electrode, but at the same time volumes higher than $40 \mu \mathrm{L}$ formed aggregates too large to be stacked in the surface for long periods of time, deteriorating any graphene benefits in the electrochemical responses. At the sight of these results, $40 \mu \mathrm{L}$ was the selected volume for preparing the graphene-modified electrode.
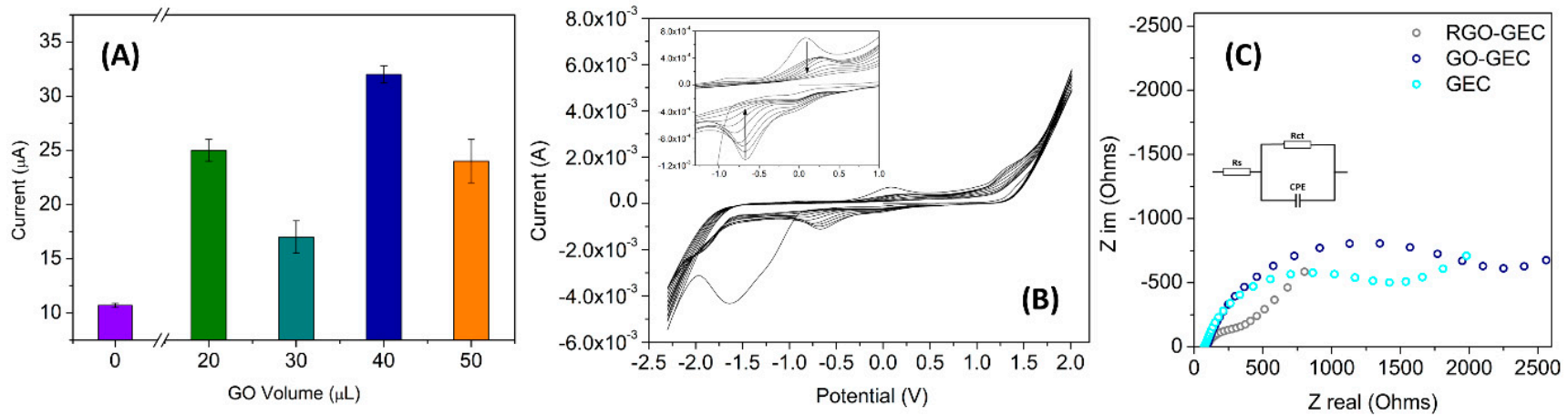

Figure 5. Optimization of the critical parameters for the use of the sensor. In (A) the deposited volume of GO via drop casting $(n=3)(\mathbf{B}, \mathbf{C})$ activation step of GO to RGO. (B) depiction of the 10 cycles reduction step; (C) shows the Nyquist plot after the reduction of GO.

The electrode surface was characterized also topographically via AFM, in order to visualize how the graphene was distributed onto the electrochemical platform. Figure 6A shows the surface of a bare GEC electrode, and Figure 6B,C is a representative region of a GO modified GEC electrode, all images have a scanned surface of $10 \times 10 \mu \mathrm{m}$. As it can be seen in Figure 6A, the GEC electrode presents a crumpled surface with a root mean square roughness $\left(\mathrm{R}_{\mathrm{RMS}}\right)$ of $73.5 \mathrm{~nm}$; meanwhile, the surface modified with GO has a $R_{R M S}$ of $123.3 \mathrm{~nm}$. Those values, along with the AFM images, verify the presence of graphene flakes. Moreover, the 3D AFM image (Figure 6C) indicates the presence of multiple and separated GO flakes, some of them clearly with less height than the others. 
Even in image 6C (marked with an arrow), it is possible to notice the GO wrinkles, also observed in TEM images (Figure 3). To sum up, AFM images demonstrated the correct stacking of GO, which lays in the surface increasing the rugosity, and consequently, the active sites of the electrode surface.
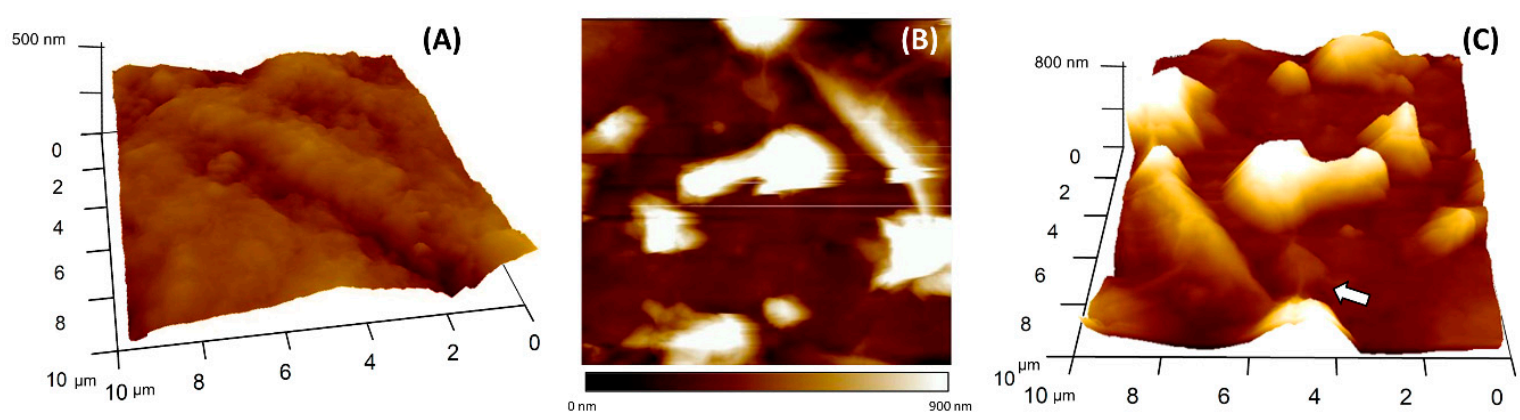

Figure 6. AFM images comparing (A) bare GEC electrode and (B) a GEC electrode modified with GO. (C) 3D AFM representation of the GO-GEC electrode.

One essential step for the building of the biosensor is the correct reduction of GO to RGO; in this work, the electrochemical reduction step was followed via CV, and verified with EIS by the comparison of the different surfaces. In Figure 5B, the CV plot corresponding to the electrochemical reduction of the GO to RGO is shown. Specifically, the good performance of the process was assessed through the oxidation and reduction peaks that appear in the range of $-1.0 \mathrm{~V}$ to $-0.5 \mathrm{~V}$ (vs. $\mathrm{Ag} / \mathrm{AgCl}$ ) (see insert on Figure $5 \mathrm{~B}$ ). According to the literature, these peaks are related to the reduction of oxygen groups present in the deposited GO in aqueous medium and neutral $\mathrm{pH}[20,53]$. An EIS technique was also used to confirm the efficiency of the electrochemical reduction. The differences in the electrode surface of the sensors can give information on the electron transfer and thus demonstrates the increment in conductivity of the RGO. In this case, the impedance characterization experiments were carried out in $\left[\mathrm{Fe}(\mathrm{CN})_{6}\right]^{3-/ 4-} 5 \mathrm{mmol} \cdot \mathrm{L}^{-1}$ between $0.5 \mathrm{MHz}$ and $0.1 \mathrm{~Hz}$ at a sinusoidal voltage perturbation of $10 \mathrm{mV}$ amplitude. Figure $5 \mathrm{C}$ shows the Nyquist plot for each modification phase; the bare GEC electrode, the electrode when the GO material was deposited and finally when the last material, RGO, was obtained. In the same figure is inserted the Randles' equivalent circuit, which includes: (i) Rs, the ohmic resistance of the bulk solution; (ii) Rct, the charge transfer resistance, which describes the difficulty of the electrochemical reaction; and (iii) CPE, a constant phase element, the component that gives information on the double layer capacitance. Figure $5 \mathrm{C}$ shows a smaller Rct for RGO-GEC electrode $(206 \Omega)$ than for GEC $(1638 \Omega)$ and GO-GEC $(2256 \Omega)$, indicating that the conductivity of graphene is regenerated with the electrochemical method applied in this work. Additionally, the data demonstrate the better conductivity of the RGO-modified electrode than the non-modified one.

These observations allowed us to confirm that GO is deposited correctly onto the GEC surface using $40 \mu \mathrm{L}$; moreover, it could be assumed that the reduction method is good enough to recover the conductive properties of graphene and proceed to covalently immobilize the enzyme via the EDAC reaction.

\subsection{Characterization and Application of the Biosensor}

\subsubsection{Electrochemical Response of the Laccase Biosensor}

Once the enzyme was immobilized, EIS was used to compare and contrast the biosensor against the already-evaluated platform.

The results of Table 2 compare Rs, Rct and CPE values for the most significant steps of the electrode modification. The most characteristic value in impedance results is the Rct; in this case, it is easy to see the little difference between the electrodes, RGO $(206 \Omega)$ and the laccase-RGO (231 $\Omega$ ) electrodes, which expose less resistance to the current flow than the bare one $(1638 \Omega)$. The effects seen in Rct of the laccase-RGO electrode could be explained 
with the negative charge formed in the carboxylic groups of the amino acids, which are deprotonated at $\mathrm{pH}$ 7.4, generating a minimal increase in the electronic transference between the electrode surface and the negative complex used as analyte. Moreover, $\mathrm{CPE}$, a complex value with empirical significance, was adjusted. The results indicate changes that may be related to the double layer capacitance thickens the decrease. Rs, as mentioned above, describes the bulk features of the solution and the diffusion characteristics; therefore, it may not be affected by the modifications on the electrode surface as can be observed in the table, indicating the ideal situation.

Table 2. Fitted values of circuit elements in the equivalent electric circuit for the different studied surfaces.

\begin{tabular}{cccc}
\hline Electrode & Rs $(\boldsymbol{\Omega})$ & Rct $(\boldsymbol{\Omega})$ & CPE (F) \\
\hline GEC & $240.7 \pm 4$ & $1638 \pm 62$ & $7.9 \times 10^{-5} \pm 0.7 \times 10^{-5}$ \\
RGO & $252.0 \pm 3$ & $206 \pm 142$ & $4.2 \times 10^{-5} \pm 0.5 \times 10^{-5}$ \\
Laccase-RGO & $252.0 \pm 2$ & $231 \pm 138$ & $4.3 \times 10^{-5} \pm 0.4 \times 10^{-5}$ \\
\hline
\end{tabular}

Finally, the resulting biosensor was tested versus a phenolic compound, catechol, which is a standard substrate of the laccase enzyme. In Figure 7A is shown the excellent performance of the enzyme by the comparison of the responses of each sensor against different concentrations of catechol. Note that the anodic peak was used as the analytical signal in the following experiments since, contrary to what was expected, it is the part where the synergistic effect of all the system elements was best [54-56]. In the calibration curves, observed a linear trend from 2 to $100 \mu \mathrm{mol} \cdot \mathrm{L}^{-1}$ for the biosensor and a wider range for the bare and the RGO electrodes was observed, which goes from 2 to $1500 \mu \mathrm{mol} \cdot \mathrm{L}^{-1}$ and from 2 to $800 \mu \mathrm{mol} \cdot \mathrm{L}^{-1}$ respectively. In the same image is also noted a clear enhancement in the sensitivity of the system, increasing by more than threefold the initial slope value.
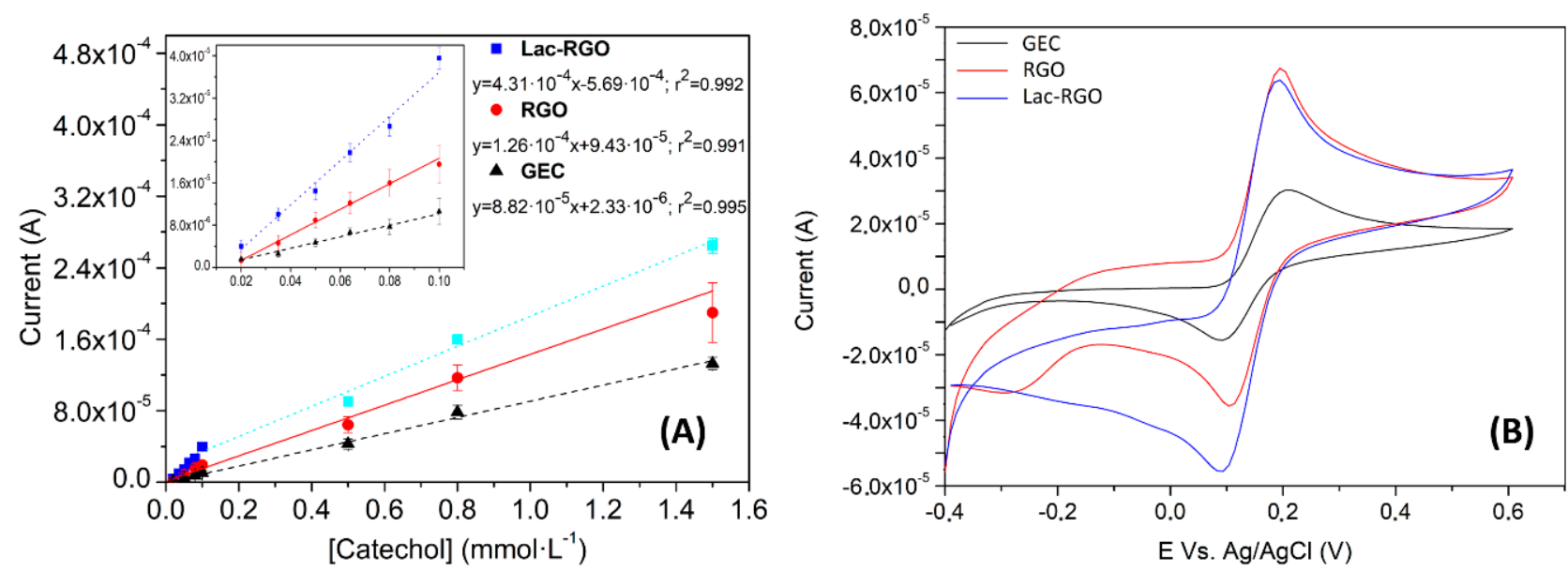

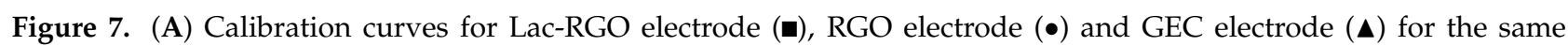
concentrations of catechol. Currents for the oxidative peak (B) CV voltammograms response of the three electrodes in the same concentration of catechol. Measures in phosphate buffer $+\mathrm{KCl}$ solution, $\mathrm{pH}$ 7.4.

Figure 7B compares GEC, RGO, and Lac-RGO responses against the same concentration of catechol. In the figure, as expected from the previous characterization, a current enhancement can be observed when the GEC electrode is modified with graphene. On the other side, some differences are appreciated when RGO and Lac-RGO responses are compared, which leads us to assume the laccase activity. Two of the most characteristic changes are observed in the oxidation baseline and the reduction peak. These facts are caused by the catalysis of the anodic reaction, and consequently there is a significant enlargement of the cathodic pathway. 


\subsubsection{Analytical Characterization of the Biosensor}

Once the biosensor operation was confirmed, their analytical properties were studied in detail. The properties studied were the linear range, limit of detection (LOD), limit of quantification (LOQ), repeatability, intermediate precision, selectivity, and lifetime.

The linear range is generally defined as the area in the calibration curve where the signals are directly proportional to the concentration. This parameter is typically evaluated using the correlation coefficient. As can be observed in the inset of Figure 7A, the linear range found spanned from 2 to $100 \mu \mathrm{mol} \cdot \mathrm{L}^{-1}$. The correlation coefficient for this range was 0.992 , indicating a satisfactory linearity.

Regarding the LOD and LOQ, there are multiple ways to calculate them, such as the use of the calibration curve for the target analyte (see Equation (1), where $\mathrm{m}$ is the slope of the calibration curve and $\sigma$ the standard deviation of the response at a $95 \%$ confidence level), the measure of signal/noise ratio or by the use of the blank standard deviation $[57,58]$. In this work, we used the first option, obtaining an LOD of $2.1 \mu \mathrm{mol} \cdot \mathrm{L}^{-1}$ and a LOQ of $7.7 \mu \mathrm{mol} \cdot \mathrm{L}^{-1}$.

$$
\mathrm{LOD}=\frac{3.3 \sigma}{m} \mathrm{LOQ}=\frac{10.0 \sigma}{m}
$$

The repeatability is defined for the European Medicines Agency (EMEA) as the "term that expresses the precision under the same operating conditions over a short interval of time" [59]. In this case, 10 consecutive measurements of a $50 \mu \mathrm{mol} \cdot \mathrm{L}^{-1}$ catechol solution were performed, obtaining a relative standard deviation (RSD) value equal to $8 \%$. Moreover, a second repeatability test was done to check the reliability of the biosensor during the day. For this purpose, 3 calibration experiments were repeated in 3 different time instants of the day (9 a.m., 1 p.m. and 4 p.m., see Figure 8A). The results showed an RSD for each point of the curve not larger than $8 \%$. All repeatability tests were taken as positive, considering that a group of data is significantly equal when the RSD value is lower than $10 \%$. In the EMEA guideline, is also defined the intermediate precision [59]. This term expresses "the within-laboratories variations, for example, when considering different days of analysis, different analyst or analysis in different equipment". This test measured, across three different days, three different calibration curves, from three regenerated biosensors, checking at the same time two parameters, the difference between days and the difference of the electrode surface regeneration procedure (see Figure 8B). The findings indicated that there were no differences between the regenerated electrodes or the measurements on different days (RSD $=6 \%$ ). The last studied parameter was the lifetime of the biosensor (or the intermediate precision of different days). To perform this test, an electrode was stored in the fridge at $4{ }^{\circ} \mathrm{C}$ in a closed Eppendorf and a measurement was done every day (without regeneration of the surface) using a $50 \mu \mathrm{mol} \cdot \mathrm{L}^{-1}$ catechol solution. The RSD results were $3 \%(n=3)$.

To visualize the selectivity of the biosensor, a Principal Component Analysis (PCA) (executed in Matlab R2020a) was carried out to show the ability of the biosensor to distinguish between the different substances considered. In particular, six substances from different families were analyzed with a Lac-RGO-modified electrode. As can be seen in Figure 9, the score plot shows that substances without phenols in their molecular structure as ibuprofen and cadaverine have similar behaviors to the buffer response. This fact demonstrates then the correct performance against the specific substrates. 

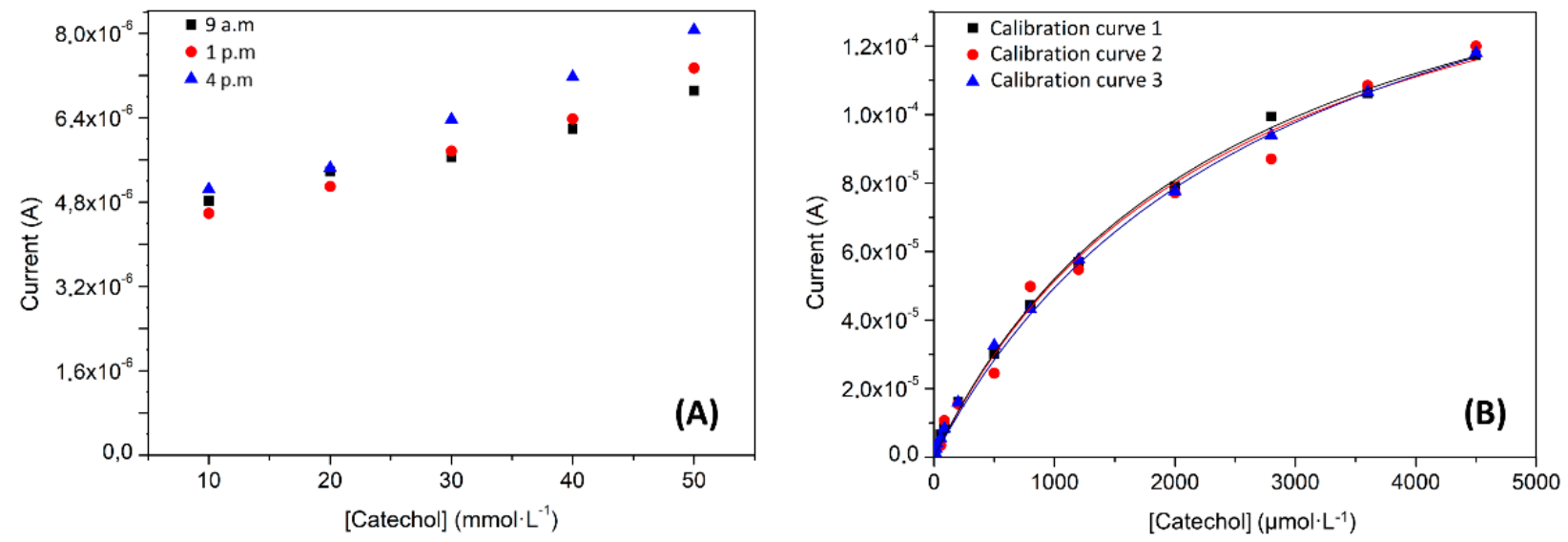

Figure 8. Study of the Lac-RGO analytical biosensor properties, (A) calibration curves repeatability test; measurements carried out in three-time instants and without regeneration of the electrode, (B) intermediate precision test made with 3 calibration curves on 3 different days with renewed electrode surface.

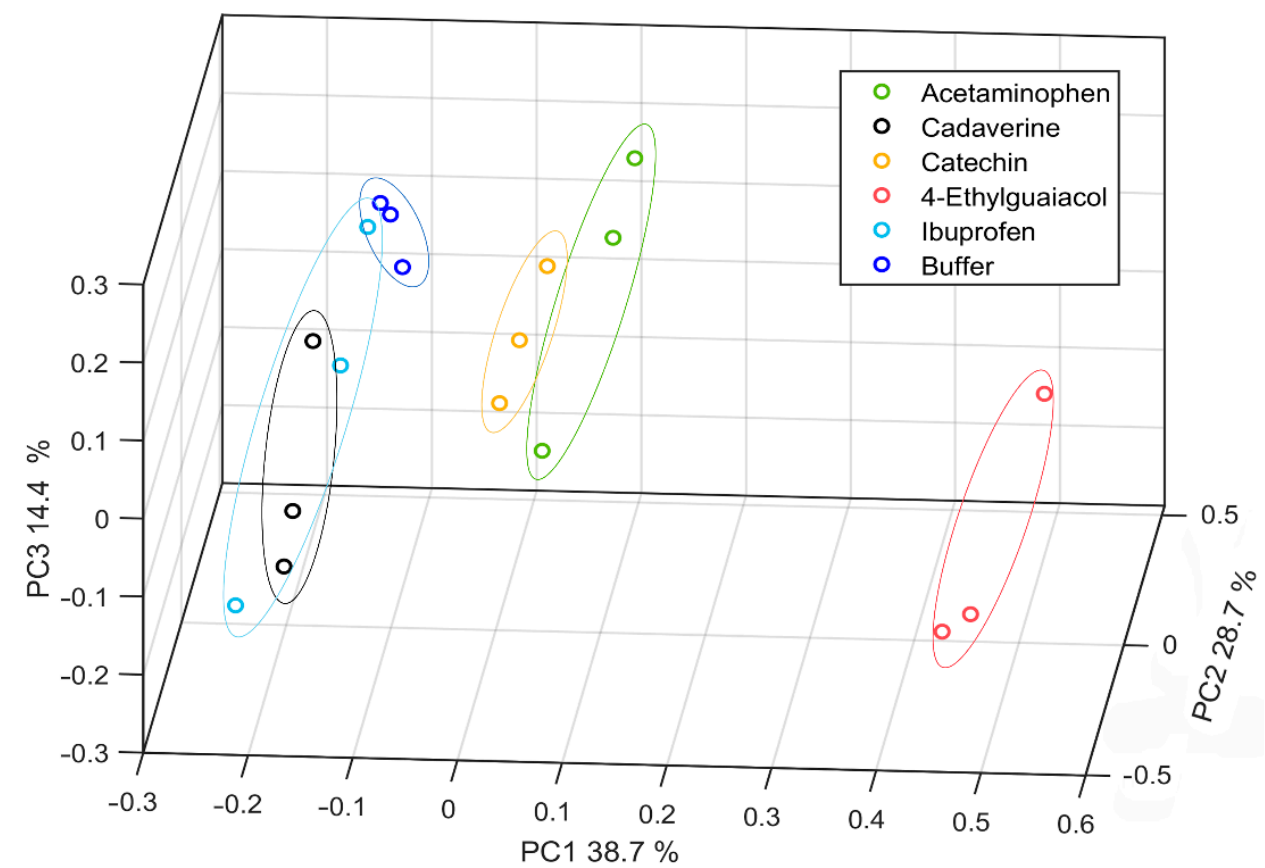

Figure 9. PCA Score plot for the three principal components of 6 different molecules, acetaminophen, cadaverine, catechin, 4-Ethylguaiacol, and ibuprofen.

Table 3 was built to compare the results in the presented work with the others in the literature. From here, it can be concluded that our biosensor has a similar behavior to devices with similar properties, even if it is compared with electrodes that include more than one catalytic material. 
Table 3. Reported values for the analytical study of sensors and biosensors for the quantification of catechol.

\begin{tabular}{|c|c|c|c|c|c|}
\hline Method & Electrode & LOD $(\mu \mathrm{M})$ & Sensitivity $\left(\mu \mathbf{A} \cdot \mu \mathbf{M}^{-1}\right)$ & Linear Range $(\mu \mathrm{M})$ & Ref \\
\hline $\mathrm{CV}$ & $\mathrm{Lac} / \mathrm{rGO} / \mathrm{GEC}$ & 2.1 & $0.431\left(15.39 \mu \mathrm{A} \mu \mathrm{M}^{-1} \mathrm{~cm}^{-2}\right)$ & $2-100$ & - \\
\hline $\mathrm{CV}$ & Tyrosinase-polysaccharide & 6 & 0.001 & $60-800$ & {$[60]$} \\
\hline $\mathrm{CV}$ & $\mathrm{Lac}^{\mathrm{P} A N I} / \mathrm{GCE}^{1}$ & 2.07 & 0.23 & $3.2-19.6$ & [55] \\
\hline $\mathrm{CV}$ & $\mathrm{Lac} / \mathrm{AA} / \mathrm{LuPc}^{3}$ & 0.58 & 0.36 & $4-150$ & {$[62]$} \\
\hline $\mathrm{CV}$ & AuNPs/ZnO/Al2O3/GO/chitosan/GCE & 3.1 & - & $0.5-40$ & [63] \\
\hline $\mathrm{CV}$ & FePP/MWCNT/Nafion/GCE ${ }^{4}$ & 3.75 & 0.1867 & $65-1600$ & {$[64]$} \\
\hline Amp. ${ }^{11}$ & N-OMC/PVA/Lac/AuE ${ }^{5}$ & 0.31 & 0.29 & $0.39-8.98$ & {$[65]$} \\
\hline Amp & $\mathrm{Lac} / \mathrm{PAP} / \mathrm{MWCNTs} / \mathrm{SPE}^{7}$ & 0.20 & $5.8 \times 10^{4}$ & $0.63-20.7$ & [47] \\
\hline Amp & Lac/Nafion/MWCNTs/SPE & 0.45 & $1.6 \times 10^{4}$ & $1.4-65.4$ & [47] \\
\hline Amp & $\mathrm{Lac} / \mathrm{MWCNTs} / \mathrm{SPE}$ & 0.73 & $1.5 \times 10^{4}$ & $2.4-134.4$ & [47] \\
\hline DPV & Lac/MWCNT-COOH/AuNPs/SDBS/PEDOT/GCE ${ }^{8}$ & 12.26 & 0.012 & $12.0-94.1$ & [67] \\
\hline DPV & RGO-MWCNT/GCE & 1.8 & 0.07 & $5.5-540$ & {$[68]$} \\
\hline DPV & 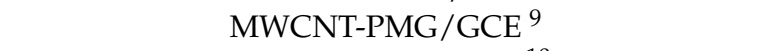 & 5.8 & $1.3 \mu \mathrm{A} \mu \mathrm{M}^{-1} \mathrm{~cm}^{-2}$ & $30-1190$ & [69] \\
\hline DPV & MWCNT/PMT/GCE 10 & 0.05 & 1.895 & $0.5-150$ & [70] \\
\hline
\end{tabular}

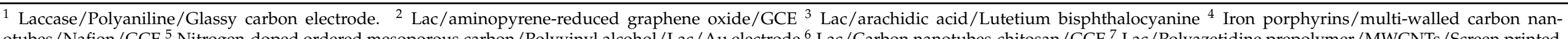

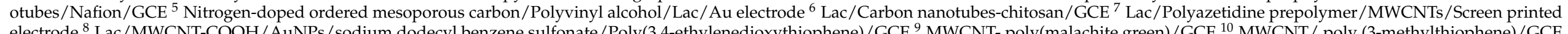

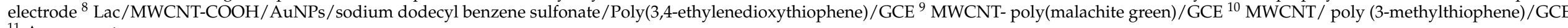
${ }^{11}$ Amperometry. 


\subsubsection{Kinetic and Inhibition Study}

The kinetics in enzymatic studies is one of the most interesting features as it is unique for each enzyme and substrate. For this reason, this issue is normally studied in detail; Leonor Michaelis and Maud Menten developed one of the most common models. This relates the enzyme substrate concentration ([S]) with the reaction rate (V). In this model, the enzyme rate depicts a saturation curve arriving to a steady state situation. At this point, the reaction rate achieves its maximum $\left(\mathrm{V}_{\max }\right)$. This typical behavior is clearly observable in Figures 7A and 8B. From here, Michaelis and Menten deduced their equation (Equation (2)), where $\mathrm{K}_{\mathrm{M}}$ is the Michaelis-Menten's constant, defined as the concentration of substrate needed to reach half of the maximum rate [71]. It is important to take into account that the $K_{M}$ and $V_{\max }$ values will be unique for each pair of enzyme and substrate.

To determine experimentally these parameters, the Lineweaver-Burk linearization is normally used (see its tailored version in Equation (3)) [72]. However, to assure that the Michaelis-Menten kinetics are valid for the studied system, first, the Hills coefficient ( $h$, see Equation (4)) is commonly calculated. In this way, when h results are being close to 1 , a Michaelis-Menten model can be assumed.

In this work, the h estimated value from the catechol calibration curve was $0.99 \pm 0.09$, demonstrating that the Lac-RGO biosensor followed the already explained kinetics. The rate parameters $\mathrm{K}_{\mathrm{M}}$ and $\mathrm{V}_{\max }$, obtained from Equation (4), were $2.62 \pm 0.50 \mu \mathrm{mol} \cdot \mathrm{L}^{-1}$ and $1.90 \times 10^{-4} \pm 0.13 \times 10^{-4} \mathrm{~A}$, respectively.

$$
\begin{aligned}
& \mathrm{V}_{0}=\mathrm{V}_{\max } \frac{[\mathrm{S}]}{[\mathrm{S}]+\mathrm{K}_{\mathrm{M}}} \\
& \frac{1}{\mathrm{~V}}=\frac{\mathrm{K}_{\mathrm{M}}}{\mathrm{V}_{\max }} \cdot \frac{1}{[\mathrm{~S}]}+\frac{1}{\mathrm{~V}_{\max }} \\
& \mathrm{V}=\frac{\mathrm{V}_{\max } \cdot\left([\mathrm{S}] / \mathrm{K}_{\mathrm{M}}\right)^{\mathrm{h}}}{1+\left([\mathrm{S}] / \mathrm{K}_{\mathrm{M}}\right)^{\mathrm{h}}}
\end{aligned}
$$

As commented in the introduction section, there are common household products that have been used for a long period of time, that are now under scrutiny due to their possible effects on the environment and health. Examples are the emerging pollutants found in cosmetics, processed food, or pharmaceutical compounds. The inhibition study of the Lac-RGO biosensor was carried out using benzoic acid and EDTA, two examples of CECs. Benzoic acid is a colorless crystalline compound that is widely used in pharmaceutical products either as an active product ingredient (for its antifungal properties) or as an excipient (as a lubricant in tablets). Both in the food and cosmetics industry, it is used as a preservative $[73,74]$. On the other hand, EDTA is a colorless and soluble product used in various and distinct applications; for example, in the paper industry as a metal chelate agent or in the food and cleaning industries as a preservative [75,76]. Regarding the legislated limits for the herein target compounds, there is not an individual value. Nevertheless, the WHO made preliminary studies that recommend as maximum values $5 \mathrm{mg} \cdot \mathrm{kg}^{-1}$ for the benzoic acid and $600 \mu \mathrm{g} \cdot \mathrm{L}^{-1}$ for the EDTA (values for drinking-water) [77,78].

Any substance that in a particular context can decrease the kinetics of an enzyme will be considered as an enzymatic inhibitor. As mentioned before, the Michaelis-Menten constants (Equation (2)) are unique for a specific enzyme-substrate system, so the presence of inhibitors will lead to renaming the $\mathrm{K}_{\mathrm{M}}$ and $\mathrm{V}_{\max }$ to $\mathrm{K}_{\mathrm{M}}^{\prime}$ and $\mathrm{V}_{\max }^{\prime}$.

There are three modelled scenarios [23]. The first situation is competitive inhibition, where the inhibitor and the substrate compete for the same active site; thus, $\mathrm{K}_{\mathrm{M}}<\mathrm{K}_{\mathrm{M}}^{\prime}$ and $\mathrm{V}_{\max }=\mathrm{V}^{\prime}{ }_{\max }$. The second situation is named non-competitive inhibition; in this case, the inhibitor is not a direct competitor but is bound in an allosteric site that deactivates the enzyme. The changes in the constants are noted as $K_{M}=K_{M}^{\prime}$ and $V_{\max }>V_{\max }^{\prime}$. Finally, the last scenario is the uncompetitive inhibition, where the inhibitor is bound, producing a 
bigger affinity between the substrate and the enzyme, leading to fewer active sites in the system, in that case $\mathrm{K}_{\mathrm{M}}>\mathrm{K}_{\mathrm{M}}^{\prime}$ and $\mathrm{V}_{\max }=\mathrm{V}_{\max }^{\prime}$ [72].

Experimentally, the changes can be elucidated comparing the Lineweaver-Burk linearization for different concentrations of inhibitor. In this sense, Figures 10 and 11 show the inhibition effects of different concentrations of benzoic acid and EDTA in a Lac-RGO electrode. Both figures show a typical behavior of the first scenario: a competitive inhibition. Figures $10 \mathrm{~A}$ and $11 \mathrm{~A}$ depict the calibration curves of catechol using a Lac-RGO electrode in the presence of different concentrations of benzoic acid and EDTA, respectively. Zone 1 highlighted the steady $V_{\max }$ and zone 2 in the increase in $\mathrm{K}_{\mathrm{M}}$ with the inhibitor concentration. In Table 4 there are complementary data used to corroborate the conclusions from Figures 10A and 11A; concretely, it includes the slopes from the $\mathrm{K}_{M}^{\prime}$ and $\mathrm{V}^{\prime}{ }_{\max }$ (calculated from the linear regressions on Figures $10 \mathrm{~A}$ and $11 \mathrm{~A}$ ), when inhibitor concentrations are varied. In this table, positive slopes confirm the Michaelis constant increase (significant variation of $\mathrm{K}_{\mathrm{M}}^{\prime}$ with slope values above uncertainties), and the constant trend for the maximum velocity (the uncertainties include the zero-slope value). This state is supported by Figure $10 B, C$ and Figure $11 B, C$, where the calculated $K_{M}{ }^{\prime}$ and $V_{\text {max }}$ ' values, and their trends, are plotted.
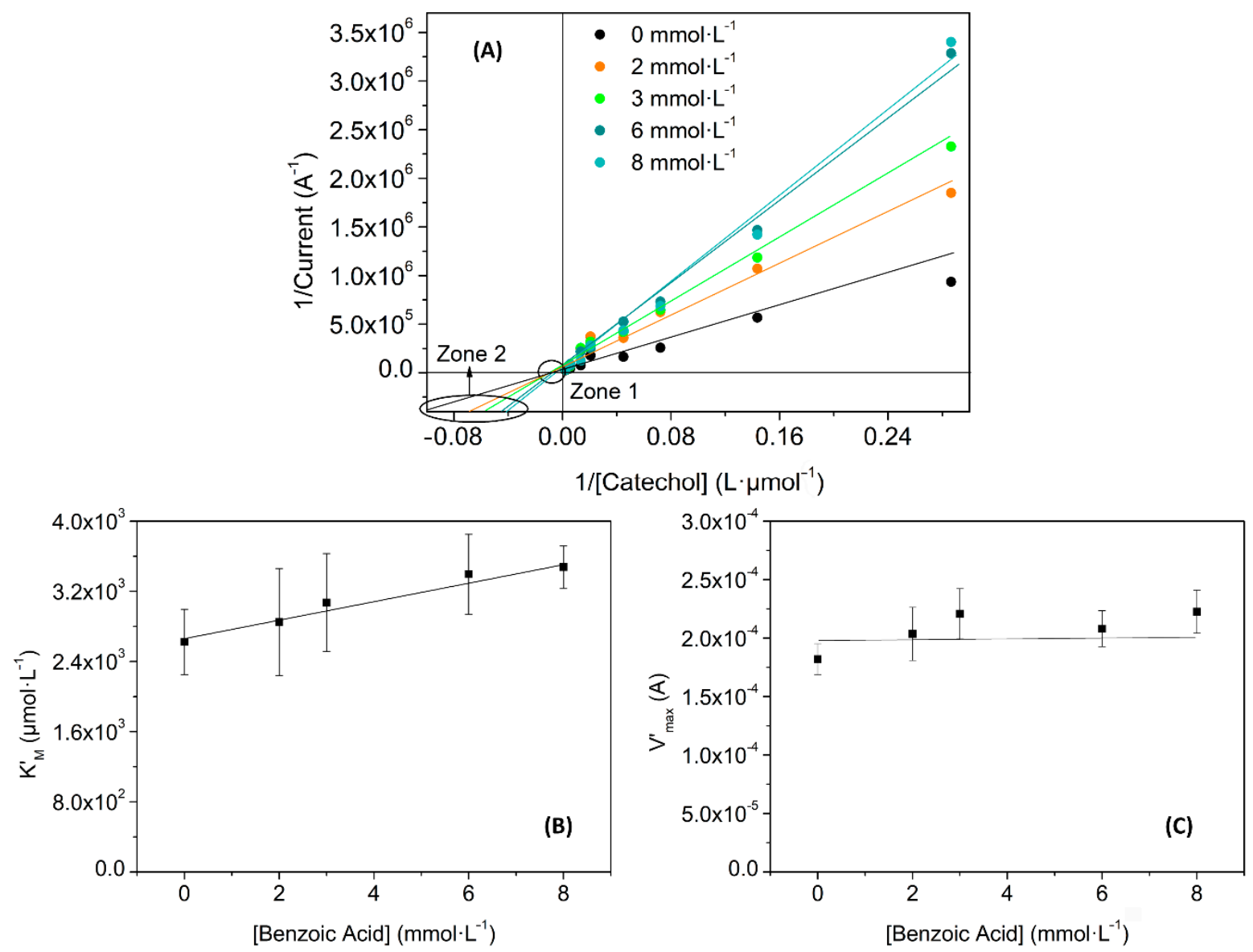

Figure 10. Biosensors kinetic study, (A) Lineweaver-Burk linearization for four benzoic acid concentrations; (B) representation of the obtained $\mathrm{K}_{M}^{\prime}$ values for each inhibitor concentration; and $(\mathbf{C}) \mathrm{V}^{\prime}$ max obtained values for each inhibitor concentration. 


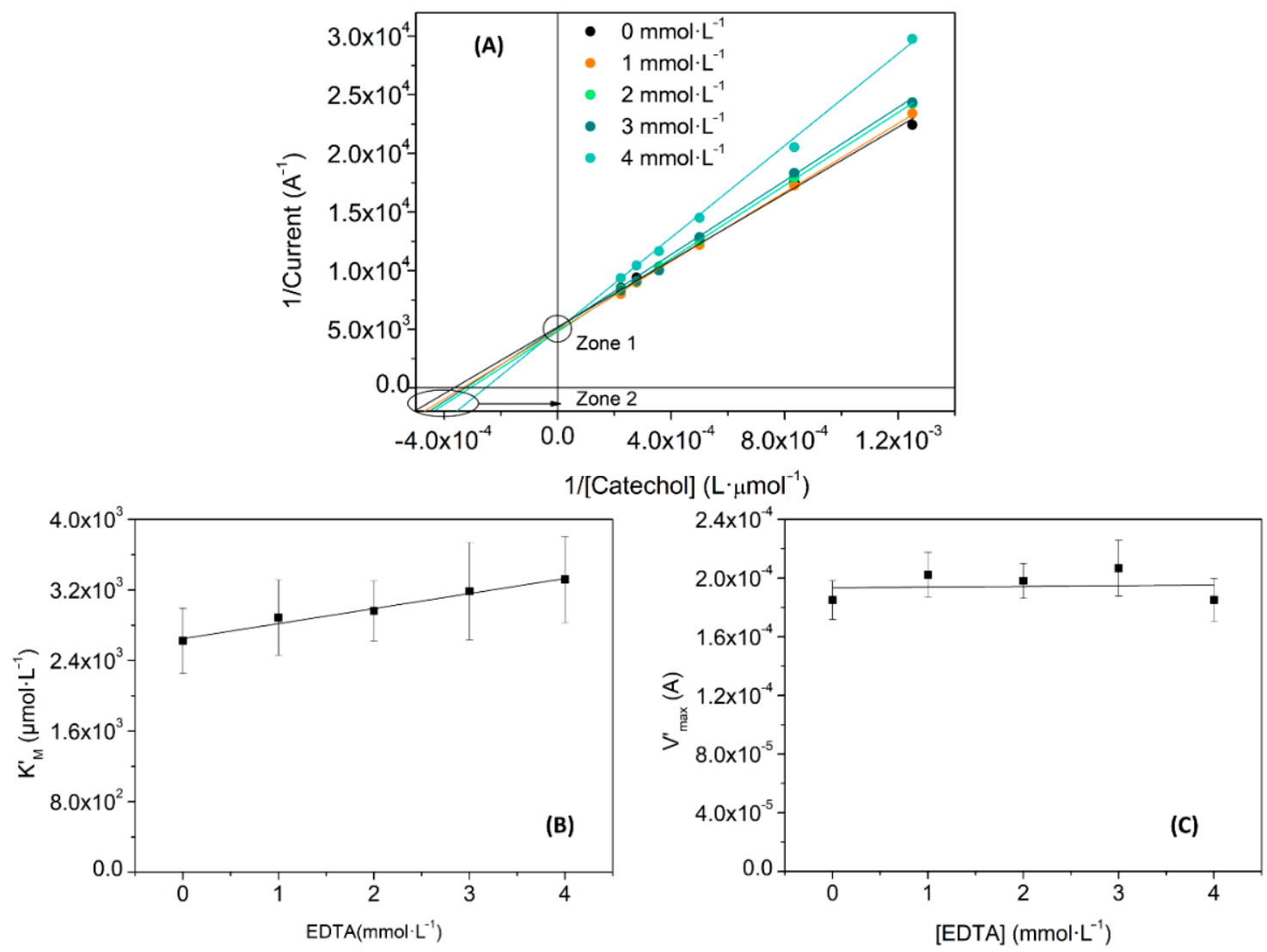

Figure 11. Biosensors kinetic study, (A) Lineweaver-Burk linearization for four EDTA concentrations; (B) representation of the obtained $\mathrm{K}_{\mathrm{M}}^{\prime}$ values for each inhibitor concentration; and $(\mathbf{C}) \mathrm{V}_{\max }^{\prime}$ obtained values for each inhibitor concentration.

Table 4. Variation of kinetic parameters vs. inhibitor concentration. Values of the linear trend $\mathrm{K}_{\mathrm{M}}^{\prime}$ and $V^{\prime}$ max vs. Inhibitor concentration when kinetics of the laccase enzyme is evaluated. Inhibition values from calibration curves of catechol in different concentrations of acid benzoic and EDTA inhibitors.

\begin{tabular}{|c|c|c|c|}
\hline Substance & $\begin{array}{c}\text { Slope of } K_{M}^{\prime} \\
\left(\mu \mathrm{mol} \cdot \mathrm{L}^{-1}\right) \text { vs. }[\mathrm{I}]\end{array}$ & $\begin{array}{c}\text { Slope of } V^{\prime} \text { max } \\
\left(A \cdot L \cdot \text { mmol }^{-1}\right) \text { vs. [I] }\end{array}$ & $\mathrm{K}_{\mathrm{I}}\left(\mathrm{mmol} \cdot \mathrm{L}^{-1}\right)$ \\
\hline Benzoic acid & $0.11 \pm 0.04$ & $3 \cdot 10^{-6} \pm 6 \cdot 10^{-6}$ & $25 \pm 19$ \\
\hline EDTA & $0.2 \pm 0.1$ & $0 \pm 1 \cdot 10^{-5}$ & $17 \pm 9$ \\
\hline
\end{tabular}

Moreover, the inhibition constant $\left(\mathrm{K}_{\mathrm{I}}\right)$ for each inhibitor. Table 4 shows the higher affinity of benzoic acid $\left(25 \mathrm{mmol} \cdot \mathrm{L}^{-1}\right)$ to Laccase than EDTA $\left(17 \mathrm{mmol} \cdot \mathrm{L}^{-1}\right)$. To calculate $\mathrm{K}_{\mathrm{I}}$ values, expression (5), corresponding to competitive inhibition, was used.

$$
\mathrm{K}_{\mathrm{M}}^{\prime}=\mathrm{K}_{\mathrm{M}} \cdot\left(1+\frac{[\mathrm{I}]}{\mathrm{K}_{\mathrm{I}}}\right)
$$

On a further visualization of the inhibition effect, Figure 12B,D shows the percentage of the inhibition achieved for each pollutant in $800 \mu \mathrm{mol} \cdot \mathrm{L}^{-1}$ of catechol. A bigger effect for benzoic acid, as expected from the previous comments, was fulfilled. In detail, a maximum $\approx 60 \%$ of inhibition was reached for the benzoic acid system in front of the $\approx 25 \%$ for EDTA. Voltammograms presented in Figure 12A,C shows the biosensor response in front of the catechol in the presence or absence of the inhibitor. In each case, the shape of the RGO voltammogram profile is recovered (Figure 7B) when benzoic acid and EDTA are in solution, indicating that laccase has lost its activity when they are present. To sum 
up, the expected inhibition effect was verified, permitting the quantification of EDTA and benzoic acid in controlled samples.
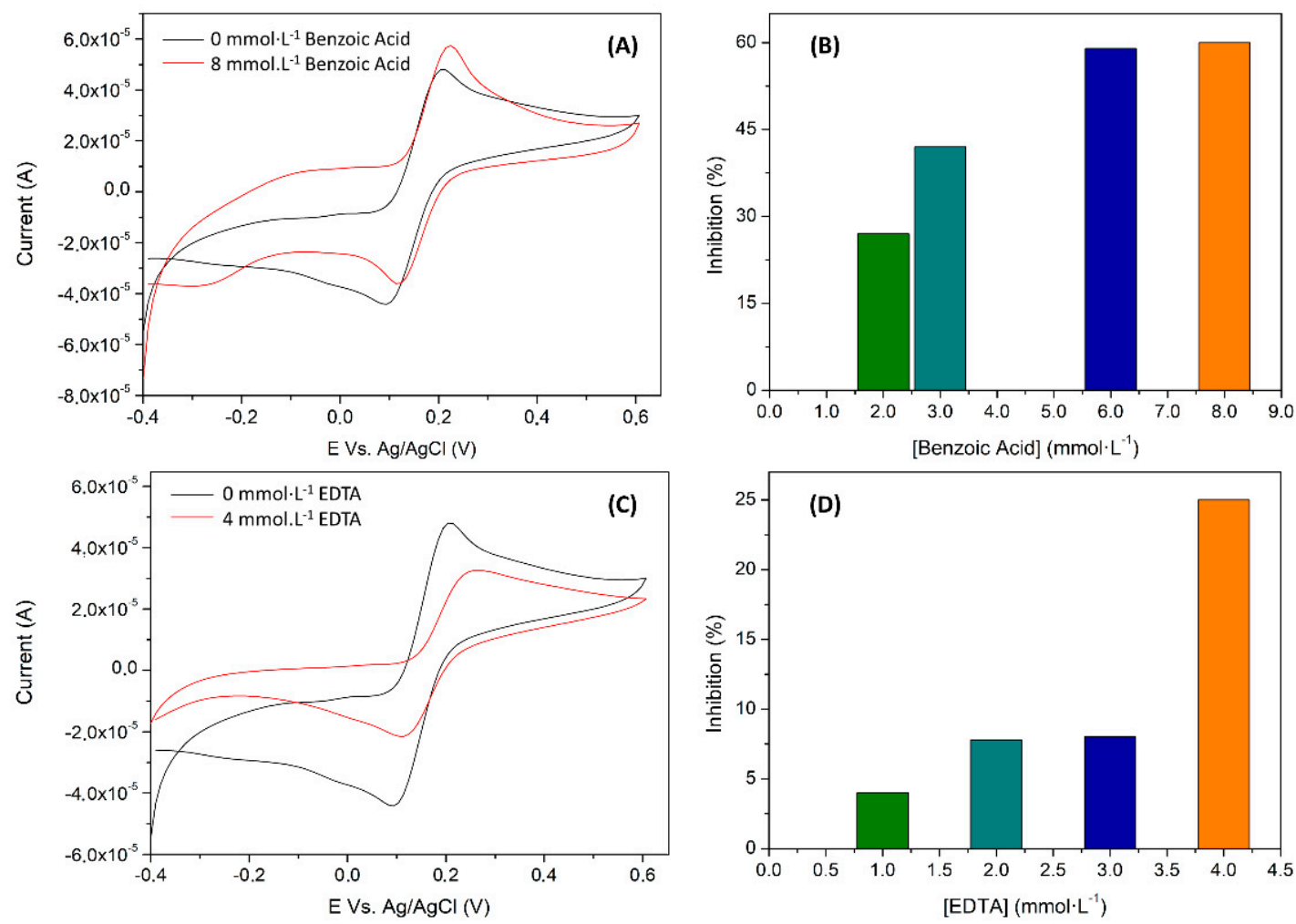

Figure 12. Biosensor inhibition study in a constant concentration of catechol $\left(800 \mu \mathrm{mol} \cdot \mathrm{L}^{-1}\right)$ when different concentrations of $(\mathbf{A}, \mathbf{B})$ benzoic acid and $(\mathbf{C}, \mathbf{D})$ EDTA inhibitors are present in the sample. $(\mathbf{A}, \mathbf{C})$ depicts the CV obtained for the maximum inhibition percentage and (B,D) the inhibition percentage profile when varying the inhibitor concentration. Percentage of inhibition calculated according to the relative maximum rate velocities, $100 \cdot\left(1-\mathrm{V}^{\prime} / \mathrm{V}\right)$.

\section{Conclusions}

The reported work has shown the capabilities of graphene as a nanomaterial to improve and facilitate the development of electrochemical biosensors, specifically those employing redox enzymes. The advantages observed can be attributed to two factors: the first one is the amelioration of the electrochemical transduction properties, thanks to inherent electrical characteristics of graphene. The second, the conjunction with the chemical properties of the material, as it serves as a linkage platform for immobilization of biomolecules such as enzymes.

All this makes this combination an unbeatable choice for electrochemical biosensing. The case specified in here, the biosensing of catechol, has demonstrated an improvement of sensitivity of ca. 30\%, which in turn improves the direct determination of phenolic compounds or opens the door to consider inhibition. In this inhibitory biosensing application, two different chemicals, EDTA and benzoate, have been verified as inhibitors of the enzyme reaction, which may constitute the basis for a future analytical device or system to monitor CECs in water.

Author Contributions: Conceptualization, M.d.V.; methodology, M.d.V.; Investigation, M.B.-S.-E. and N.F.M.; writing-original draft preparation, M.B.-S.-E.; writing—review and editing, M.d.V.; supervision, M.d.V.; funding acquisition, M.d.V. All authors have read and agreed to the published version of the manuscript. 
Funding: This research was funded by the Spanish Government (Ministerio de Economía y Competitividad) grant number PID2019-107102RB-C21. M.B.S. was funded by Secretaria d'Universitats i Recerca del Departament d'Empreses i Coneixement de la Generalitat de Catalunya and by European Social Fund, European Union through a FI fellowship. M.d.V. thanks the support from program ICREA Academia.

Institutional Review Board Statement: Not applicable.

Informed Consent Statement: Not applicable.

Data Availability Statement: Not applicable.

Acknowledgments: The authors thanks to Anna Herrera Chacón from the Universitat Autònoma de Barcelona for her collaboration with TEM images and to M.J Esplandiu from ICN2, for the AFM study.

Conflicts of Interest: The authors declare no conflict of interest.

\section{References}

1. Hulanicki, A.; Glab, S.; Ingman, F. Chemical sensors: Definitions and classification. Pure Appl. Chem. 1991, 63, 1247-1250. [CrossRef]

2. Novoselov, K.S.; Geim, A.K.; Morozov, S.V.; Jiang, D.; Zhang, Y.; Dubonos, S.V.; Grigorieva, I.V.; Firsov, A.A. Electric field effect in atomically thin carbon films. Science 2004, 306, 666-669. [CrossRef]

3. Tung, T.T.; Nine, M.J.; Krebsz, M.; Pasinszki, T.; Coghlan, C.J.; Tran, D.N.H.; Losic, D. Recent advances in sensing applications of graphene assemblies and their composites. Adv. Funct. Mater. 2017, 27, 1702891. [CrossRef]

4. Pasinszki, T.; Krebsz, M.; Tung, T.T.; Losic, D. Carbon nanomaterial based biosensors for non-invasive detection of cancer and disease biomarkers for clinical diagnosis. Sensors 2017, 17, 1919. [CrossRef]

5. Medina-Plaza, C.; García-Hernández, C.; de Saja, J.A.; Fernández-Escudero, J.A.; Barajas, E.; Medrano, G.; García-Cabezón, C.; Martin-Pedrosa, F.; Rodriguez-Mendez, M.L. The advantages of disposable screen-printed biosensors in a bioelectronic tongue for the analysis of grapes. LWT Food Sci. Technol. 2015, 62, 940-947. [CrossRef]

6. Zhou, M.; Zhai, Y.; Dong, S. Electrochemical sensing and biosensing platform based on chemically reduced graphene oxide. Anal. Chem. 2009, 81, 5603-5613. [CrossRef] [PubMed]

7. Suhito, I.R.; Koo, K.M.; Kim, T.H. Recent advances in electrochemical sensors for the detection of biomolecules and whole cells. Biomedicines 2021, 9, 15. [CrossRef]

8. Ocaña, C.; Lukic, S.; del Valle, M. Aptamer-antibody sandwich assay for cytochrome c employing an MWCNT platform and electrochemical impedance. Microchim. Acta 2015, 182, 2045-2053. [CrossRef]

9. Serrano, N.; Prieto-Simón, B.; Cetó, X.; Del Valle, M. Array of peptide-modified electrodes for the simultaneous determination of $\mathrm{Pb}(\mathrm{II}), \mathrm{Cd}(\mathrm{II})$ and $\mathrm{Zn}(\mathrm{II})$. Talanta 2014, 125, 159-166. [CrossRef]

10. Bélanger, D.; Pinson, J. Electrografting: A powerful method for surface modification. Chem. Soc. Rev. 2011, 40, 3995-4048. [CrossRef]

11. Sun, C.-L.; Su, C.-H.; Wu, J.-J. Synthesis of short graphene oxide nanoribbons for improved biomarker detection of Parkinson's disease. Biosens. Bioelectron. 2015, 67, 327-333. [CrossRef]

12. Martín, A.; Batalla, P.; Hernández-Ferrer, J.; Martínez, M.T.; Escarpa, A. Graphene oxide nanoribbon-based sensors for the simultaneous bio-electrochemical enantiomeric resolution and analysis of amino acid biomarkers. Biosens. Bioelectron. 2015, 68, 163-167. [CrossRef]

13. Barua, S.; Geng, X.; Chen, B. Graphene-based nanomaterials for healthcare applications. In Photonanotechnology for Therapeutics and Imaging; Choi, S.-K., Ed.; Micro and Nano Technologies; Elsevier: Amsterdam, The Netherlands, 2020 ; pp. 45-81. ISBN 978-0-12-817840-9.

14. Pottathara, Y.B.; Grohens, Y.; Kokol, V.; Kalarikkal, N.; Thomas, S. Synthesis and processing of emerging two-dimensional nanomaterials. In Nanomaterials Synthesis; Pottathara, B.Y., Thomas, S., Kalarikkal, N., Grohens, Y., Kokol, V., Eds.; Micro and Nano Technologies; Elsevier: Amsterdam, The Netherlands, 2019; pp. 1-25. ISBN 978-0-12-815751-0.

15. Smith, A.T.; La Chance, A.M.; Zeng, S.; Liu, B.; Sun, L. Synthesis, properties, and applications of graphene oxide/reduced graphene oxide and their nanocomposites. Nano Mater. Sci. 2019, 1, 31-47. [CrossRef]

16. Hummers, W.S.; Offeman, R.E. Preparation of graphitic oxide. J. Am. Chem. Soc. 1958, 80, 1339. [CrossRef]

17. Marcano, D.C.; Kosynkin, D.V.; Berlin, J.M.; Sinitskii, A.; Sun, Z.; Slesarev, A.; Alemany, L.B.; Lu, W.; Tour, J.M. Improved synthesis of graphene oxide. ACS Nano 2010, 4, 4806-4814. [CrossRef] [PubMed]

18. Aceta, Y.; del Valle, M. Graphene electrode platform for impedimetric aptasensing. Electrochim. Acta 2017, 229, 458-466. [CrossRef]

19. Xu, J.; Wang, Y.; Hu, S. Nanocomposites of graphene and graphene oxides: Synthesis, molecular functionalization and application in electrochemical sensors and biosensors. A review. Microchim. Acta 2017, 184, 1-44. [CrossRef]

20. Toh, S.Y.; Loh, K.S.; Kartom Kamarudin, S.; Ramli, W.; Daud, W. Graphene production via electrochemical reduction of graphene oxide: Synthesis and characterisation. Chem. Eng. J. 2014, 251, 422-434. [CrossRef] 
21. Dreyer, D.R.; Park, S.; Bielawski, C.W.; Ruoff, R.S. The chemistry of graphene oxide. Chem. Soc. Rev. 2010, 39, 228-240. [CrossRef]

22. Pumera, M. Graphene-based nanomaterials and their electrochemistry. Chem. Soc. Rev. 2010, 39, 4146-4157. [CrossRef]

23. Jian, X.; Liu, X.; Yang, H.M.; Guo, M.M.; Song, X.L.; Dai, H.Y.; Liang, Z.H. Graphene quantum dots modified glassy carbon electrode via electrostatic self-assembly strategy and its application. Electrochim. Acta 2016, 190, 455-462. [CrossRef]

24. Bonet-San-Emeterio, M.; Algarra, M.; Petković, M.; del Valle, M. Modification of electrodes with N-and S-doped carbon dots. Evaluation of the electrochemical response. Talanta 2020, 212, 120806. [CrossRef]

25. Algarra, M.; González-Calabuig, A.; Radotić, K.; Mutavdzic, D.; Ania, C.O.; Lázaro-Martínez, J.M.; Jiménez-Jiménez, J.; RodríguezCastellón, E.; del Valle, M. Enhanced electrochemical response of carbon quantum dot modified electrodes. Talanta 2018, 178, 679-685. [CrossRef] [PubMed]

26. Shereema, R.M.; Rao, T.P.; Sameer Kumar, V.B.; Sruthi, T.V.; Vishnu, R.; Prabhu, G.R.D.; Sharath Shankar, S. Individual and simultaneous electrochemical determination of metanil yellow and curcumin on carbon quantum dots based glassy carbon electrode. Mater. Sci. Eng. C 2018, 93, 21-27. [CrossRef] [PubMed]

27. Merkoçi, A.; Pumera, M.; Llopis, X.; Pérez, B.; Del Valle, M.; Alegret, S. New materials for electrochemical sensing VI: Carbon nanotubes. TrAC Trends Anal. Chem. 2005, 24, 826-838. [CrossRef]

28. Cipri, A.; Del Valle, M. Pd nanoparticles/multiwalled carbon nanotubes electrode system for voltammetric sensing of tyrosine. J. Nanosci. Nanotechnol. 2014, 14, 6692-6698. [CrossRef]

29. Moore, R.R.; Banks, C.E.; Compton, R.G. Basal plane pyrolytic graphite modified electrodes: Comparison of carbon nanotubes and graphite powder as electrocatalysts. Anal. Chem. 2004, 76, 2677-2682. [CrossRef]

30. Fusco, G.; Bollella, P.; Mazzei, F.; Favero, G.; Antiochia, R.; Tortolini, C. Catalase-based modified graphite electrode for hydrogen peroxide detection in different beverages. J. Anal. Methods Chem. 2016, 2016, 1-12. [CrossRef] [PubMed]

31. Montañez, J.L.; Ramos, E.G.; Alegret, S.; Delgado, R.J. Biosensor de glucosa basado en un biocompósito disperso de grafito-epoxiplatino-glucosa oxidasa. Inf. Technol. 2011, 22, 29-40. [CrossRef]

32. Zacco, E.; Pividori, M.I.; Alegret, S.; Galve, R.; Marco, M.P. Electrochemical magnetoimmunosensing strategy for the detection of pesticides residues. Anal. Chem. 2006, 78, 1780-1788. [CrossRef]

33. Tuomela, M.; Hatakka, A. Oxidative fungal enzymes for bioremediation. In Comprehensive Biotechnology; Moo-Young, M., Ed.; Pergamon: Oxford, UK, 2019; pp. 224-239. ISBN 978-0-444-64047-5.

34. Rodríguez-Couto, S. Solid-state fermentation for laccases production and their applications. In Current Developments in Biotechnology and Bioengineering; Pandey, A., Larroche, C., Soccol, C.R., Eds.; Elsevier: Amsterdam, The Netherlands, 2018 ; pp. 211-234. ISBN 978-0-444-63990-5.

35. Zandaryaa, S. Chemical contaminants: Those invisible additives in our drink. A World Sci. 2011, 9, 18-21.

36. Frye, C.; Bo, E.; Calamandrei, G.; Calzà, L.; Dessì-Fulgheri, F.; Fernández, M.; Fusani, L.; Kah, O.; Kajta, M.; Le Page, Y.; et al. Endocrine disrupters: A review of some sources, effects, and mechanisms of actions on behaviour and neuroendocrine systems. J. Neuroendocrinol. 2012, 24, 144-159. [CrossRef]

37. Monneret, C. What is an endocrine disruptor? C. R. Biol. 2017, 340, 403-405. [CrossRef] [PubMed]

38. Diamanti-Kandarakis, E.; Bourguignon, J.P.; Giudice, L.C.; Hauser, R.; Prins, G.S.; Soto, A.M.; Zoeller, R.T.; Gore, A.C. Endocrinedisrupting chemicals: An endocrine society scientific statement. Endocr. Rev. 2009, 30, 293-342. [CrossRef] [PubMed]

39. Céspedes, F.; Martínez-Fàbregas, E.; Alegret, S. New materials for electrochemical sensing I. Rigid conducting composites. TrAC Trends Anal. Chem. 1996, 15, 296-304. [CrossRef]

40. Alegret, S.; Alonso, J.; Bartrolí, J.; Céspedes, F.; Martínez-Fàbregas, E.; del Valle, M. Amperometric biosensors based on bulkmodified epoxy graphite biocomposites. Sens. Mater. 1996, 8, 147-153.

41. Kalinke, C.; de Oliveira, P.R.; Bonet-San-Emeterio, M.; González-Calabuig, A.; del Valle, M.; Salvio Mangrich, A.; Humberto Marcolino Junior, L.; Bergamini, M.F. Voltammetric electronic tongue based on carbon paste electrodes modified with biochar for phenolic compounds stripping detection. Electroanalysis 2019, 31, 2238-2245. [CrossRef]

42. Eng, A.Y.S.; Ambrosi, A.; Chua, C.K.; Šaněk, F.; Sofer, Z.; Pumera, M. Unusual inherent electrochemistry of graphene oxides prepared using permanganate oxidants. Chem. A Eur. J. 2013, 19, 12673-12683. [CrossRef]

43. Bonet-San-Emeterio, M.; González-Calabuig, A.; del Valle, M. Artificial neural networks for the resolution of dopamine and serotonin complex mixtures using a graphene-modified carbon electrode. Electroanalysis 2019, 31, 1-9. [CrossRef]

44. Ortiz-Aguayo, D.; del Valle, M. Label-free aptasensor for lysozyme detection using electrochemical impedance spectroscopy. Sensors 2018, 18, 354. [CrossRef]

45. Ocaña, C.; Hayat, A.; Mishra, R.; Vasilescu, A.; Del Valle, M.; Marty, J.-L. A novel electrochemical aptamer-antibody sandwich assay for lysozyme detection. Analyst 2015, 140, 4153. [CrossRef]

46. Cattaruzza, F.; Cricenti, A.; Flamini, A.; Girasole, M.; Longo, G.; Prosperi, T.; Andreano, G.; Cellai, L.; Chirivino, E. Controlled loading of oligodeoxyribonucleotide monolayers onto unoxidized crystalline silicon; fluorescence-based determination of the surface coverage and of the hybridization efficiency; parallel imaging of the process by atomic force microscopy. Nucleic Acids Res. 2006, 34, 2-13. [CrossRef]

47. Tortolini, C.; Rea, S.; Carota, E.; Cannistraro, S.; Mazzei, F. Influence of the immobilization procedures on the electroanalytical performances of trametes versicolor laccase based bioelectrode. Microchem. J. 2011, 100, 8-13. [CrossRef] 
48. Khoo, W.Y.H.; Pumera, M.; Bonanni, A. Graphene platforms for the detection of caffeine in real samples. Anal. Chim. Acta 2013, 804, 92-97. [CrossRef]

49. Hui, K.H.; Ambrosi, A.; Pumera, M.; Bonanni, A. Improving the analytical performance of graphene oxide towards the assessment of polyphenols. Chem. Eur. J. 2016, 22, 3830-3834. [CrossRef]

50. Shang, N.G.; Papakonstantinou, P.; McMullan, M.; Chu, M.; Stamboulis, A.; Potenza, A.; Dhesi, S.S.; Marchetto, H. Catalyst-free efficient growth, orientation and biosensing properties of multilayer graphene nanoflake films with sharp edge planes. Adv. Funct. Mater. 2008, 18, 3506-3514. [CrossRef]

51. Haditale, M.; Dariani, R.S.; Ghasemian Lemraski, E. Electrical behavior of graphene under temperature effect and survey of I-T curve. J. Theor. Appl. Phys. 2019, 13, 351-356. [CrossRef]

52. Ambrosi, A.; Bonanni, A.; Sofer, Z.; Cross, J.S.; Pumera, M. Electrochemistry at chemically modified graphenes. Chem. A Eur. J. A Eur. J. 2011, 17, 10763-10770. [CrossRef] [PubMed]

53. Anonymous. Organic Electrochemistry: Revised and Expanded, 5th ed.; Hammerich, O., Speiser, B., Eds.; CRC Press: Boca Raton, FL, USA, 2015.

54. Palanisamy, S.; Ramaraj, S.K.; Chen, S.M.; Yang, T.C.K.; Pan, Y.F.; Chen, T.W.; Velusamy, V.; Selvam, S. A novel laccase biosensor based on laccase immobilized graphene-cellulose microfiber composite modified screen-printed carbon electrode for sensitive determination of catechol. Sci. Rep. 2017, 7, 41214. [CrossRef] [PubMed]

55. Nazari, M.; Kashanian, S.; Rafipour, R. Laccase immobilization on the electrode surface to design a biosensor for the detection of phenolic compound such as catechol. Spectrochim. Acta Part A Mol. Biomol. Spectrosc. 2015, 145, 130-138. [CrossRef] [PubMed]

56. Fernández-Sánchez, C.; Tzanov, T.; Gübitz, G.M.; Cavaco-Paulo, A. Voltammetric monitoring of laccase-catalysed mediated reactions. Bioelectrochemistry 2002, 58, 149-156. [CrossRef]

57. Harris, D.C. Quantitative Chemical Analysis, 7th ed.; Freeman and Co.: New York, NY, USA, 1948.

58. McNaught, A.D.; Wilkinson, A. The IUPAC Compendium of Chemical Terminology, 2nd ed.; Blackwell Scientific Publications: Oxford, UK, 1997; ISBN 0-9678550-9-8.

59. Borman, P.; Elder, D. Q2(R1) Validation of analytical procedures. In ICH Quality Guidelines; John Wiley \& Sons: Hoboken, NJ, USA, 2017; pp. 127-166. ISBN 9781118971147.

60. Tembe, S.; Inamdar, S.; Haram, S.; Karve, M.; D'Souza, S.F. Electrochemical biosensor for catechol using agarose-guar gum entrapped tyrosinase. J. Biotechnol. 2007, 128, 80-85. [CrossRef] [PubMed]

61. Zhou, X.H.; Liu, L.H.; Bai, X.; Shi, H.C. A reduced graphene oxide based biosensor for high-sensitive detection of phenols in water samples. Sens. Actuators B Chem. 2013, 181, 661-667. [CrossRef]

62. Medina-Plaza, C.; de Saja, J.A.; Rodriguez-Mendez, M.L. Bioelectronic tongue based on lipidic nanostructured layers containing phenol oxidases and lutetium bisphthalocyanine for the analysis of grapes. Biosens. Bioelectron. 2014, 57, 276-283. [CrossRef]

63. Nazari, M.; Kashanian, S.; Moradipour, P.; Maleki, N. A novel fabrication of sensor using $\mathrm{ZnO}^{-} \mathrm{Al}_{2} \mathrm{O}_{3}$ ceramic nanofibers to simultaneously detect catechol and hydroquinone. J. Electroanal. Chem. 2018, 812, 122-131. [CrossRef]

64. Bin, Z.; Yanhong, C.; Jiaojiao, X. Biomimetic oxidase sensor based on functionalized surface of carbon nanotubes and iron prophyrins for catechol detection. Bioprocess Biosyst. Eng. 2018, 42, 279-290. [CrossRef]

65. Guo, M.; Wang, H.; Huang, D.; Han, Z.; Li, Q.; Wang, X.; Chen, J. Amperometric catechol biosensor based on laccase immobilized on nitrogen-doped ordered mesoporous carbon (N-OMC)/PVA matrix. Sci. Technol. Adv. Mater. 2014, 15, 1-9. [CrossRef]

66. Zhao, Q.-L.; Zhang, Z.-L.; Huang, B.-H.; Peng, J.; Zhang, M.; Pang, D.-W. Facile preparation of low cytotoxicity fluorescent carbon nanocrystals by electrooxidation of graphite. Chem. Commun. 2008, 5116. [CrossRef]

67. Albayati, S.A.R.; Kashanian, S.; Nazari, M.; Rezaei, S. Novel fabrication of a laccase biosensor to detect phenolic compounds using a carboxylated multiwalled carbon nanotube on the electropolymerized support. Bull. Mater. Sci. 2019, 42, 1-8. [CrossRef]

68. Hu, F.; Chen, S.; Wang, C.; Yuan, R.; Yuan, D.; Wang, C. Study on the application of reduced graphene oxide and multiwall carbon nanotubes hybrid materials for simultaneous determination of catechol, hydroquinone, $\mathrm{p}$-cresol and nitrite. Anal. Chim. Acta 2012, 724, 40-46. [CrossRef] [PubMed]

69. Umasankar, Y.; Periasamy, A.P.; Chen, S.M. Electrocatalysis and simultaneous determination of catechol and quinol by poly(malachite green) coated multiwalled carbon nanotube film. Anal. Biochem. 2011, 411, 71-79. [CrossRef] [PubMed]

70. Zhang, H.; Zhao, J.; Liu, H.; Liu, R.; Wang, H.; Liu, J. Electrochemical determination of diphenols and their mixtures at the multiwall carbon nanotubes/poly (3-methylthiophene) modified glassy carbon electrode. Microchim. Acta 2010, 169, $277-282$. [CrossRef]

71. Berg, J.M.; Tymoczko, J.L.; Stryer, L. The Michaelis-Menten model accounts for the kinetic properties of many enzymes. In Biochemistry; W H Freeman: New York, NY, USA, 2002.

72. Roskoski, R. Michaelis-Menten Kinetics; Elsevier: Amsterdam, The Netherlands, 2015.

73. Hazan, R.; Levine, A.; Abeliovich, H. Benzoic acid, a weak organic acid food preservative, exerts specific effects on intracellular membrane trafficking pathways in saccharomyces cerevisiae. Appl. Environ. Microbiol. 2004, 70, 4449-4457. [CrossRef] [PubMed]

74. Nair, B. Final report on the safety assessment of benzyl alcohol, benzoic acid, and sodium benzoate. Int. J. Toxicol. 2001, 20, 23-50. [CrossRef] [PubMed]

75. Wolf, K.; Gilbert, P.A. EDTA—Ethylenediaminetetraacetic acid. In Detergents. Anthropogenic Compounds; de Oude, N.T., Ed.; Springer: Berlin/Heidelberg, Germany, 1992; Volume 3, pp. 243-259.

76. Oviedo, C.; Rodríguez, J. EDTA: The chelating agent under environmental scrutiny. Quim. Nova 2003, 26, 901-905. [CrossRef] 
77. World Health Organization \& International Programme on Chemical Safety. Benzoic Acid and Sodium Benzoate; Concise International Chemical Assessment Document, 26; World Health Organization: Geneva, Switzerland, 2000.

78. World Health Organization \& International Programme on Chemical Safety. Health criteria and other supporting information. In Guidelines for Drinking-Water Quality; World Health Organization: Geneva, Switzerland, 1996; ISBN 9241544805. 